\title{
Mass and heat transfer model of tubular solar still
}

\begin{abstract}
In this paper, a new mass and heat transfer model of a Tubular Solar Still (TSS) was proposed incorporating various mass and heat transfer coefficients taking account of the humid air properties inside the still. The heat balance of the humid air and the mass balance of the water vapor in the humid air were formulized for the first time. As a result, the proposed model enabled to calculate the diurnal variations of the temperature, water vapor density and relative humidity of the humid air, and to predict the hourly condensation flux besides the temperatures of the water, cover and trough, and the hourly evaporation flux. The validity of the proposed model was verified using the field experimental results carried out in Fukui, Japan and Muscat, Oman in 2008. The diurnal variations of the calculated temperatures and water vapor densities had a good agreement with the observed ones. Furthermore, the proposed model can predict the daily and hourly production flux precisely.
\end{abstract}

Keyword: Condensation; Convection; Evaporation; Mass heat transfer model; Humid air; Tubular Solar Still (TSS) 